\title{
Childhood trajectories of peer victimization and prediction of mental health outcomes in midadolescence: a longitudinal population- based study
}

\author{
Marie-Claude Geoffroy PhD, Michel Boivin PhD, Louise Arseneault PhD, Johanne Renaud MD MSc, \\ Léa C. Perret MSc, Gustavo Turecki MD PhD, Gregory Michel PhD, Julie Salla PhD, Frank Vitaro PhD, \\ Mara Brendgen PhD, Richard E. Tremblay PhD, Sylvana M. Côté PhD
}

Cite as: CMAJ 2018 January 15;190:E37-43. doi: 10.1503/cmaj.170219

CMAJ Podcasts: author interview at https://soundcloud.com/cmajpodcasts/170219-res

Visual abstract available at www.cmaj.ca/lookup/suppl/doi:10.1503/cmaj.170219/-/DC2

\begin{abstract}
BACKGROUND: Exposure to peer victimization is relatively common. However, little is known about its developmental course and its effect on impairment associated with mental illnesses. We aimed to identify groups of children following differential trajectories of peer victimization from ages 6 to 13 years and to examine predictive associations of these trajectories with mental health in adolescence.
\end{abstract}

METHODS: Participants were members of the Quebec Longitudinal Study of Child Development, a prospective cohort of 2120 children born in 1997/98 who were followed until age 15 years. We included 1363 participants with selfreported victimization from ages 6 to
13 years and data available on their mental health status at 15 years.

RESULTS: We identified 3 trajectories of peer victimization. The 2 prevailing groups were participants with little or moderate exposure to victimization (441/1685 [26.2\%] and 1000/1685 [59.3\%], respectively); the third group (244 [14.5\%]) had been chronically exposed to the most severe and long-lasting levels of victimization. The most severely victimized individuals had greater odds of reporting debilitating depressive or dysthymic symptoms (odds ratio [OR] 2.56, 95\% confidence interval $[\mathrm{Cl}]$ 1.27-5.17), debilitating generalized anxiety problems (OR 3.27, $\mathrm{Cl} 1.64-$ 6.51) and suicidality (OR $3.46, \mathrm{Cl} 1.53-7.81$ ) at 15 years than those exposed to the lowest levels of victimization, after adjustment for sex, childhood mental health, family hardship and victimization perpetration. The association with suicidality remained significant after controlling for concurrent symptoms of depression or dysthymia and generalized anxiety problems.

INTERPRETATION: Adolescents who were most severely victimized by peers had an increased risk of experiencing severe symptoms consistent with mental health problems. Given that peer victimization trajectories are established early on, interventions to reduce the risk of being victimized should start before enrolment in the formal school system. eer victimization is harm caused by peers acting outside the norms of appropriate conduct. ${ }^{1}$ It includes (but is not limited to) bullying, which is characterized by an imbalance of power between the perpetrator and the victim. Peer victimization has been prospectively associated with a broad range of internalizing and externalizing symptoms $\mathrm{s}^{2-4}$ and mental health problems ${ }^{5-12}$ in childhood and adolescence, even after factors associated with victimization have been taken into account. It can be reduced through intervention, ${ }^{13,14}$ which thus represents a promising avenue to improve adolescents' mental health at the population level. However, there is a gap in scientific knowledge, because no study has captured the development of victimization from the beginning of the school years to the transition to high school while documenting its impact on impairment associated 
with mental health problems. This is an important period in the life course, because social relationships are developing (i.e., laying the foundation for future relationships), peer victimization is at its highest rate, ${ }^{4}$ and mental health problems are emerging. ${ }^{15}$

In this study, we aimed to capture, at the population level, differential exposure to peer victimization assessed from 6 to 13 years of age, and predictive associations of such victimization with mental health problems at 15 years, while adjusting for a variety of potential confounders. It has been shown that a substantial proportion of those who have been victimized have also bullied others. ${ }^{7,16}$ Because perpetrators tend to display higher levels of aggression ${ }^{7}$ and conduct problems, ${ }^{17}$ we tested whether victimization increased the risk of symptoms of mental illness above and beyond the perpetration of victimization.

\section{Methods}

\section{Participants}

Participants were members of the Quebec Longitudinal Study of Child Development, a population-based sample of 2120 individuals born in 1997/98 in the Canadian province of Quebec. For more details about the larger study design, please see www. jesuisjeserai.stat.gouv.qc.ca/default_an.htm.

Of the 1821 individuals invited at the 15-year data collection point, 1466 participated, including 1443 who completed mental health questions, and 1363 of this latter group also provided information on victimization trajectories $(64.3 \%$ of the original 2120; Appendix 1, available at www.cmaj.ca/lookup/suppl/ doi:10.1503/cmaj.170219/-/DC1). Participants who were underrepresented were more likely to be male (428/757 [56.5\%] for those excluded from analyses v. 642/1363 [47.1\%] for those included in analyses, $\chi^{2}=22.54, p<0.001$ ), to be of nonwhite ethnicity $\left(119 / 756\right.$ [15.7\%] v. 68/1361 [5.0\%], $\chi^{2}=69.67, p<$ 0.001 ), to have parents with low socioeconomic status (Z scores -0.16 v. $\left.0.08, t_{2093}=-5.21, p<0.001\right)$ and to have mothers with high depressive symptoms ( 1.50 v. 1.35 [on a scale from 0 to $10], t_{1445.9}=2,37 p=0.02$ ).

\section{Adolescent mental health outcomes at 15 years}

At age 15 years, participants completed the Mental Health and Social Inadaptation Assessment, ${ }^{18}$ to assess the frequency, in the past 12 months (where 1 = never, 2 = sometimes, and $3=$ often), of depression and dysthymia problems (Cronbach $\alpha=0.90 ; 8$ items), generalized anxiety problems (Cronbach $\alpha=0.86 ; 9$ items), social anxiety problems (Cronbach $\alpha=0.90 ; 7$ items), eating problems (Cronbach $\alpha=0.70 ; 5$ items), oppositional or defiance problems (Cronbach $\alpha=0.84 ; 9$ items) and conduct problems (Cronbach $\alpha=0.95 ; 16$ items). We also asked participants to rate the severity (as "not at all," "slightly," "somewhat" or "a lot") of any associated impairments across 4 domains of daily functioning (home, school, friendship or romantic relationships, daily occupations). Although the Mental Health and Social Inadaptation Assessment is not a diagnostic tool, its items have been designed to reflect the symptoms reported in the Diagnostic and Statistical Manual of Mental Disorders, 5th edition (Appendix 2, part 1, available at www.cmaj.ca/lookup/suppl/doi:
10.1503/cmaj.170219/-/DC1). Adolescents in the top $10 \%$ of symptoms were classified as having mental health problems.

We measured suicidality in terms of having serious thoughts of wanting to die (as indicated by an affirmative answer to the question, "Did you ever seriously think of attempting suicide?") or making a suicide attempt (and if so, how many attempts) in the past 12 months.

\section{Childhood peer victimization between 6 and 13 years}

We assessed peer victimization through self-rating at ages 6,7 , $8,10,12$ and 13 years using a modified version of the Self-Report Victimization Scale. ${ }^{19}$ This scale measures the occurrence of physical, verbal, relational and cyber-victimization since the beginning of the school year. All items were administered in the second half of the school year (from February to June) and are listed in Appendix 2, part 2. We coded the responses as 0 (never), 1 (once/twice or rarely) or 2 (often, more often or very often). Within each year, we averaged individual item scores and rescaled them to range between 0 and 10, to obtain a global score of victimization. Cronbach $\alpha$ for each age ranged from 0.70 to 0.80 .

\section{Childhood confounders}

We measured confounders at age 6, 7, 8, 10, 12 and 13 years, and averaged the scores across ages, unless otherwise indicated.

\section{Family hardship}

We determined family hardship in terms of family socioeconomic status (aggregate of annual gross income, parental education level and occupational prestige), ${ }^{20}$ family structure when the child was 13 years of age (biological parents, blended family, single parent), family functioning as assessed with the McMaster Family Assessment (7 items; e.g., "don't get along well together"), ${ }^{21}$ hostile-reactive parenting practices ( 7 items; e.g., "use physical punishment") ${ }^{22}$ and maternal depressive symptoms when the child was 8 and 10 years of age (e.g., Center for Epidemiologic Studies Depression Scale ${ }^{23}$ ).

\section{Childhood mental health and victimization perpetration}

Oppositional and defiant behaviour (4 items; e.g., defiant or refused to comply), inattention and hyperactivity (9 items; e.g., "could not sit still") and physical aggression symptoms (3 items, e.g., "got into a fight") were all rated by school teachers. Anxiety symptoms (4 items; e.g., "appears fearful/nervous") were reported by mothers when the children were 6 and 8 years of age and were self-reported at ages 10, 12 and 13 years. Victimizing others was self-reported at 10, 12 and 13 years (10 items; e.g., "encouraged other children to pick on a particular child"). The questions were derived from the Canadian National Longitudinal Study of Children and Youth, ${ }^{21}$ which incorporates items from the Child Behaviour Checklist, ${ }^{24}$ the Ontario Child Health Study scales ${ }^{25}$ and the Preschool Behaviour Questionnaire, ${ }^{26}$ with responses rated on a 3-point scale. We assessed recent (past $2 \mathrm{wk}$ ) depressive symptoms at ages 10, 12 and 13 years using the Children's Depression Inventory, short version. ${ }^{27,28}$ 


\section{Statistical analysis}

To adjust for selective attrition that may have affected our study sample of 1363, we conducted analyses with and without inverse probability weights, representing participants' probabilities of being included in the study sample conditional on sex, ethnicity, socioeconomic status and maternal depressive symptoms. The general pattern of results with and without weights did not differ; only the latter are presented here.

We examined patterns of peer victimization by age and sex using analysis of variance. To take advantage of our repeated assessments of victimization, we estimated group-based trajectories $^{29}$ of peer victimization from 6 to 13 years of age. We applied growth mixture models to identify differential exposure to victimization using Mplus (Muthén \& Muthén).

We estimated a series of models including 1 to 4 trajectory groups based on the maximum available sample $(n=1685)$. Trajectories were estimated using a method called Full Information Maximum Likelihood. With this method, each participant is used for information that the particular participant brings to the analyses; the only participants who are excluded from the models are those who are always missing. The maximum available sample of 1685 was derived from the original sample of 2120 . While those who provided data on both mental health and victimization $(n=1363)$ were included in the maximum available sample, information on victimization was not available for the rest. We then selected the best-fitting model using the Bayesian Information Criterion, LoMendellRubin likelihood ratio test and entropy. We controlled for all potential confounders that were available in our data and known for their associations with victimization. Appendix 3 , part 1 (available at www.cmaj.ca/lookup/suppl/doi:10.1503/ cmaj.170219/-/DC1), presents bivariable associations between confounders and peer victimization trajectories. Then, we examined whether the victimization trajectories were predictive of adolescents' mental health using hierarchical logistic regressions. The associations were adjusted for sex (model 1), childhood family hardship (socioeconomic status, family functioning and structure, hostile-reactive parenting, maternal depressive symptoms; model 2), childhood mental health (depression, anxiety, inattention/hyperactivity, oppositional/ defiant behaviour and physical aggression symptoms; model 3) and victimization perpetration (model 4).

All interactions with sex were nonsignificant ( $p$ values for sex interaction: $p=0.5$ for depression/dysthymia problem, $p=0.7$ for generalized anxiety problem, $p=0.7$ for social anxiety problem, $p=0.4$ for suicidality, $p>0.9$ for eating problem, $p=0.2$ for oppositional/defiant problem, $p=0.6$ for conduct problem); therefore, we present results for both sexes combined. Data were missing for less than $6 \%$ of participants for all covariables, except for maternal depressive symptoms (where data were missing for $12 \%$ ). To minimize further data loss, we imputed missing information on confounders using multiple imputations by the chained equations method, ${ }^{30}$ and we conducted analyses across the 10 imputed data sets. Patterns of results were identical for both maximum available participants and the imputed samples.

\section{Ethics approval}

The Ethics Committee of the Institut de la statistique du Québec and the Research Ethics Board of the CHU Sainte-Justine Research Center approved each phase of the study, and informed consent was obtained.

\section{Results}

The sociodemographic characteristics of the 1363 participants included in the analysis are presented in Table 1.

As shown in Table 2, peer victimization declined for males and females as they grew older. Males reported more victimization than females: marginally more at age 6 but significantly more at all later ages.

Figure 1 depicts trajectories of victimization according to the 3-group model (based on the maximum available sample of 1685), and its caption reports the fit indices for the 1- to 4-group models.

Table 1: Sociodemographic characteristics of the study sample

\begin{tabular}{|lc|}
\hline Sharacteristic & $\begin{array}{c}\text { No. }(\%) \text { of } \\
\text { participants } \\
n=1363\end{array}$ \\
\hline Sex of child & \\
\hline Male & $642(47.1)$ \\
\hline Female & $721(52.9)$ \\
\hline Maternal age at birth of target child, yr & \\
\hline$<21$ & $70(5.1)$ \\
\hline$\geq 21$ & $1293(94.9)$ \\
\hline Maternal education & \\
\hline High school diploma or higher & $1138(83.5)$ \\
\hline No high school diploma & $224(16.4)$ \\
\hline Missing & $1(0.1)$ \\
\hline Paternal education & $1027(75.3)$ \\
\hline High school diploma or higher & $238(17.5)$ \\
\hline No high school diploma & $98(7.2)$ \\
\hline Missing & $1180(86.6)$ \\
\hline Sufficiency of family income & $4(0.3)$ \\
\hline Sufficient income & $1071(78.6)$ \\
\hline Insufficient income & $278(20.4)$ \\
\hline Missing & $14(1.0)$ \\
\hline Family status & \\
\hline Biological parents & \\
\hline Blended/single parent & \\
\hline Missing & \\
\hline Maternal depression & \\
\hline Yes ( $\geq 2.67$ CESD) & \\
\hline No (<2.67 CESD) & \\
\hline Missing & \\
\hline Note: CESD Center for Epidemiologic Studies Depression scale. & \\
\hline
\end{tabular}


Although the Bayesian Information Criterion decreased slightly across the 1- to 4-group models, a closer examination of the 4- and 3-group models indicated that the LoMendell-Rubin likelihood ratio test and entropy favoured a 3-group model. We therefore selected a 3-group model reflecting distinct trajectories of victimization. Most of the children (1000/1685 [59.3\%]) followed a trajectory of moderate victimization, whereas 441 (26.2\%) followed a stable trajectory of no or low victimization, and 244 (14.5\%) followed a trajectory of severe victimization. There was a decrease in victimization with age for both the moderate victimization ( $p=$ $0.009)$ and severe victimization $(p<0.001)$ groups. Table 3 shows the prevalence of the 7 mental health outcomes in the 3 trajectory groups. The proportion of adolescents who reported mental health problems at 15 years of age increased with the severity of peer victimization (all $p$ values $<0.05$ ).

Table 2: Global peer victimization score by age and sex*

\begin{tabular}{|lccc|}
\multicolumn{4}{c}{ Sex; peer victimization score, $\dagger$} \\
mean \pm SD \\
$\begin{array}{l}\text { Age at } \\
\text { victimization, yr }\end{array}$ & Males & Females & p value \\
\hline $6(n=1169)$ & $3.79 \pm 2.69$ & $3.52 \pm 2.58$ & 0.08 \\
\hline $7(n=1474)$ & $3.51 \pm 2.40$ & $3.18 \pm 2.36$ & 0.008 \\
\hline $8(n=1467)$ & $3.58 \pm 2.44$ & $3.22 \pm 2.32$ & 0.004 \\
\hline $10(n=1310)$ & $3.48 \pm 2.29$ & $2.80 \pm 2.20$ & $<0.001$ \\
\hline $12(n=1343)$ & $2.75 \pm 2.14$ & $2.19 \pm 1.92$ & $<0.001$ \\
\hline $13(n=1229)$ & $1.96 \pm 1.96$ & $1.52 \pm 1.67$ & $<0.001$ \\
\hline $\begin{array}{l}\text { Note: SD = standard deviation. } \\
\text { *Based on maximum available } n \text { value. } \\
\text { †Range of global peer victimization score: } 0-10 .\end{array}$ & \\
\hline
\end{tabular}

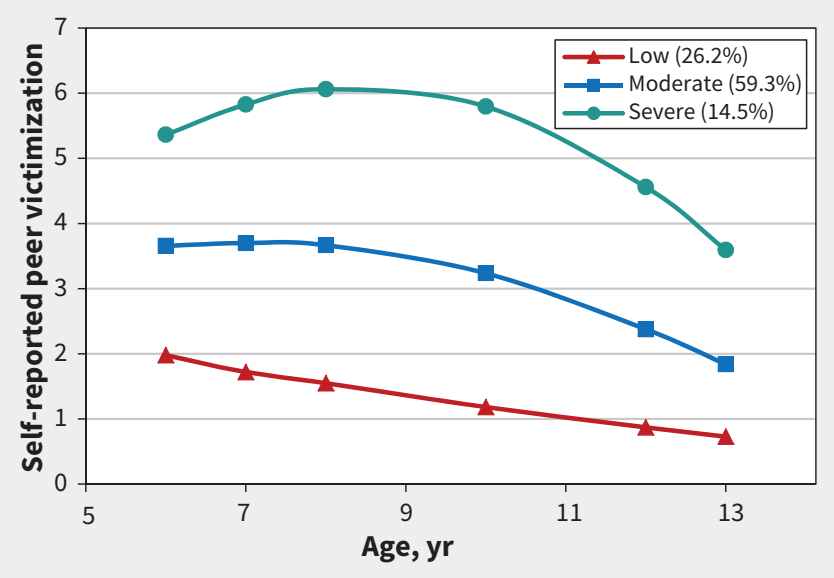

Figure 1: Developmental trajectories of victimization from 6 to 13 years of age, according to the 3-group model. The terms "low," "moderate" and "severe" refer to levels of self-reported peer victimization (\% of sample in parentheses). Fit indices for the models: for the 1-group model, Bayesian Information Criterion $(\mathrm{BIC})=34793.36$, entropy not applicable, LoMendell-Rubin likelihood ratio test (LMR-LRT) not applicable; for the 2-group model, BIC $=33712.49$, entropy $=0.62$, LMR-LRT $p<0.001$; for the 3-group model, $\mathrm{BIC}=33524.18$, entropy $=0.62$, LMR-LRT $p=0.002$; for the 4-group model, BIC $=33452.34$, entropy $=0.56$, LMR-LRT $p=0.3)$. All models were based on the maximum available sample $(n=1685)$.
Predictive associations of victimization trajectories with mental health in adolescence

Compared with the trajectory for none/low victimization, severe victimization was associated with higher odds of reporting a depression/dysthymia problem (odds ratio [OR] 2.34, 95\% confidence interval $[\mathrm{Cl}] 1.20-4.53)$, generalized anxiety problem (OR $3.32,95 \% \mathrm{Cl} 1.75-6.30$ ) or suicidality (OR 3.46 , 95\% Cl 1.53-7.81) at 15 years, with adjustment for sex, childhood family hardship, mental health and victimization perpetration (Table 4). Additionally, relative to those with the trajectory for moderate victimization, children with severe victimization had higher odds of reporting a depression/dysthymia problem (OR 1.78, 95\% Cl 1.06-2.97), generalized anxiety problem (OR 2.19, 95\% Cl 1.343.58 ), social anxiety problem (OR $1.75,95 \% \mathrm{Cl} 1.07-2.88$ ) and suicidality (OR 2.10, 95\% Cl 1.17-3.75) (Appendix 3, part 2). Children with moderate victimization in childhood did not have an increased risk of reporting mental health problems after we accounted for all confounders, except for a marginally significant association with conduct problem (Appendix 3, part 3).

We further examined the significance of longitudinal associations through sensitivity analyses of depression/dysthymia and generalized anxiety problems by considering the impairment criteria (i.e., adolescents reporting symptoms that interfered with their functioning, who answered "somewhat" or "a lot" to at least 1 of the 4 impairment questions). As shown in Table 5, adolescents who reported severe victimization had an increased risk of a debilitating depression/dysthymia problem (OR $2.56,95 \% \mathrm{Cl}$ $1.27-5.17$ ) or a debilitating generalized anxiety problem (OR 3.27, 95\% Cl 1.64-6.51) in the fully adjusted model.

Finally, we tested the possibility that severe victimization predicted suicidality (i.e., serious ideation or attempt), independent of comorbid mental health problems associated with victimization. After adjustment for reported depression/dysthymia and generalized anxiety problems at 15 years, sex, childhood family hardship, mental health and victimization perpetration, adoles-

Table 3: Prevalence of adolescent mental health by trajectories of victimization $(n=1363)$

\begin{tabular}{|c|c|c|c|}
\hline \multirow{2}{*}{$\begin{array}{l}\text { Self-reported mental } \\
\text { health problem at } \\
\text { age } 15 \mathrm{yr}\end{array}$} & \multicolumn{3}{|c|}{$\begin{array}{l}\text { Peer victimization trajectory, } 6-13 \text { yr } \\
\text { no. }(\%) \text { of participants }\end{array}$} \\
\hline & $\begin{array}{c}\text { None/low } \\
n=\mathbf{3 8 0}\end{array}$ & $\begin{array}{c}\text { Moderate } \\
n=771\end{array}$ & $\begin{array}{l}\text { Severe } \\
n=212\end{array}$ \\
\hline $\begin{array}{l}\text { Depression/dysthymia } \\
\text { problem }\end{array}$ & $25(6.6)$ & $75(9.7)$ & $37(17.5)$ \\
\hline $\begin{array}{l}\text { Generalized anxiety } \\
\text { problem }\end{array}$ & $26(6.8)$ & $79(10.2)$ & $42(19.8)$ \\
\hline Social anxiety problem & $36(9.5)$ & $74(9.6)$ & $37(17.5)$ \\
\hline Suicidality & $12(3.2)$ & $43(5.6)$ & $28(13.2)$ \\
\hline Eating problem & $40(10.5)$ & $108(14.0)$ & $38(17.9)$ \\
\hline $\begin{array}{l}\text { Oppositional/defiant } \\
\text { problem }\end{array}$ & $20(5.3)$ & $79(10.2)$ & $39(18.4)$ \\
\hline $\begin{array}{l}\text { Conduct disorder } \\
\text { problem }\end{array}$ & $18(4.7)$ & $79(10.2)$ & $34(16.0)$ \\
\hline
\end{tabular}


cents who reported severe victimization had an increased risk of suicidal ideation or attempted suicide (OR 2.76, 95\% Cl 1.16-6.54).

We repeated all analyses with adjustment for confounders that were assessed at baseline only (i.e., at $6 \mathrm{yr}$ ); the pattern of results was identical with what has been reported here (data not shown).

\section{Interpretation}

Our study captured differential trajectories of victimization over a 7-year period while documenting the consequences on a wide range of mental health problems commonly seen in today's adolescents and associated impairments. Adolescents who were severely victimized showed an increased risk of severe symptoms of certain mental health problems. Compared with other studies that have relied on victimization and exposure to bullying assessed at a single point in time, ${ }^{8,31-33}$ our trajectory analyses have the advantage of identifying patterns of victimization varying in severity and over time, highlighting a general decline in victimization with age.

Importantly, our findings showed a general tendency, in about $15 \%$ of the children, of being exposed to the most severe levels of victimization from the beginning of their education until the transition to high school. Those children were at greater risk of debilitating depressive/dysthymic symptoms or anxiety and of suicidality in adolescence than less severely victimized children, even after we accounted for a plethora of confounders assessed throughout childhood. Thus, our results, along with those of many other studies, ${ }^{4,5,8,16,34}$ suggest that severe peer victimization may contribute to the development of mental health problems in adolescence. Therefore, it is important to prevent severe victimization early in the lifespan.

Our findings also add to existing knowledge by showing that the predictive association of severe victimization with suicidality is independent of concurrent depression/dysthymia and generalized anxiety problems. This is consistent with a large body of data suggesting that suicide risk is strongly associated with, but independent of, psychopathology. ${ }^{35}$ It remains to be determined whether the effect of victimization on suicide risk is mediated by factors that have been previously found to explain part of suicide risk, such as impulsive and aggressive traits. ${ }^{36-38}$ Previous studies that included a victimized-perpetrator group reported that individuals who are both victims and perpetrators, but not those who are only victims, were at risk of externalizing problems. ${ }^{7,16}$ In this regard, severe victimization no lon-

Table 4: Results of hierarchical logistic regression for mental health problems in adolescence, for comparison of peer victimization trajectories $(n=1363)$

\begin{tabular}{|c|c|c|c|c|}
\hline \multirow{2}{*}{$\begin{array}{l}\text { Self-reported mental health } \\
\text { problem at age } 15 \mathrm{yr}\end{array}$} & \multicolumn{4}{|c|}{ Trajectory comparison model (severe v. none/low); adjusted OR $(95 \% \mathrm{CI})^{\star}$} \\
\hline & Model 1 & Model 2 & Model 3 & Model 4 \\
\hline Depression/dysthymia problem & $4.48(2.55-7.87)$ & $4.69(2.61-8.40)$ & $2.38(1.23-4.60)$ & $2.34(1.20-4.53)$ \\
\hline Generalized anxiety problem & $5.14(2.97-8.90)$ & $4.84(2.75-8.22)$ & $3.18(1.69-5.99)$ & $3.32(1.75-6.30)$ \\
\hline Social anxiety problem & $2.67(1.60-4.45)$ & $2.71(1.60-4.59)$ & $1.64(0.89-3.00)$ & $1.55(0.84-2.85)$ \\
\hline Suicidality & $6.48(3.16-13.27)$ & $5.31(2.55-11.07)$ & $3.45(1.53-7.76)$ & $3.46(1.53-7.81)$ \\
\hline Eating problem & $2.62(1.59-4.33)$ & $2.38(1.42-3.98)$ & $1.45(0.82-2.59)$ & $1.38(0.77-2.48)$ \\
\hline Oppositional/defiant problem & $4.00(2.25-7.11)$ & $3.29(1.82-5.92)$ & $2.15(1.13-4.13)$ & $1.53(0.77-3.02)$ \\
\hline Conduct disorder problem & $4.12(2-25-7-55)$ & $3.41(1.84-6.33)$ & $2.30(1.16-4.57)$ & $1.90(0.95-3.81)$ \\
\hline
\end{tabular}

Table 5: Results of hierarchical logistic regression for debilitating mental health problems in adolescence, for comparison of peer victimization trajectories $(n=1363)$

Self-reported debilitating mental health problem at age $15 \mathrm{yr}$

Depression/dysthymia problem Generalized anxiety problem

Trajectory comparison model (severe v. none/low); adjusted OR $(95 \% \mathrm{CI})^{\star}$

\section{Model 1}

$4.79(2.63-8.72)$

$5.04(2.79-9.09)$

\section{Model 2}

$4.87(2.61-9.06)$

$4.57(2.49-8.40)$
Model 3

$2.60(1.29-5.23)$

$3.24(1.64-6.43)$
Model 4

$2.56(1.27-5.17)$

$3.27(1.64-6.51)$

Note: $\mathrm{Cl}=$ confidence interval, $\mathrm{OR}=$ odds ratio

*Model 1 was adjusted for sex. Model 2 was additionally adjusted for family hardship (6-13 yr) determined as family functioning and structure ( $13 \mathrm{yr}$ ), hostile-reactive parenting, socioeconomic status and maternal depressive symptoms (8-10 yr). Model 3 was additionally adjusted for mental health (6-13 yr) determined as depressive symptoms (10-13 yr), anxiety symptoms, inattention/hyperactivity symptoms, oppositional/defiant behaviour and physical aggression symptoms. Model 4 was additionally adjusted for victimization perpetration (10-13 yr). 
ger predicted externalizing problems (e.g., oppositional/defiant behaviour and conduct), after adjustment for victimization perpetration in our models.

Finally, we found that $59.3 \%$ of the sample had been exposed to moderate levels of victimization during the first years of elementary school, but not so much thereafter. The large proportion of individuals belonging to this group could reflect the fact that our assessments covered young ages (i.e., 6-8 yr), when victimization behaviour is frequent. Moderate victimization was not predictive of mental health problems after we accounted for childhood mental health symptoms assessed concurrently with victimization.

\section{Limitations}

Our study had the following limitations. Mental health outcomes were measured by self-report questionnaires, which do not provide clinical diagnoses. We used an interference scale reflecting problems affecting daily activities to increase the chances of identifying clinically significant problems. Despite their limitations, self-report questionnaires and arbitrary cut-offs (e.g., top 10\% of scores) are commonly used to identify mental health problems in epidemiologic surveys. ${ }^{9,39}$ Furthermore, peer victimization was also selfreported, and may reflect a perception potentially biased by the participant's mental state. However, such bias was minimized, because we carefully adjusted for mental health symptoms measured concurrently with victimization. Although we controlled for a wide range of confounders, we acknowledge that uncontrolled variables could account for some of the associations. Our design does not prove causality; however, we were able to examine the temporal relation from childhood victimization to mental health in adolescence, because our prospective study design allowed adjustment for childhood mental health symptoms and other influences. Given the smaller number of males reporting mental health problems and suicidality, statistical power was low for investigating moderation by sex in the observed associations. As in all longitudinal surveys, attrition occurred, and some population subgroups were underrepresented. This differential attrition could potentially result in underestimation of associations with victimization for the most vulnerable individuals. However, the patterns of results were consistent across weighted, imputed and maximum available samples, so the bias related to selective drop-out is likely to be small.

\section{Conclusion}

More than half of the children in our study experienced moderate exposure to victimization, especially during early childhood. This finding suggests that being called names or being excluded from social groups once in a while is somewhat normal. This form of victimization was not associated with greater propensity to report mental health problems. A smaller group of children were victimized often and repeatedly over the years. Such severe victimization affected about $15 \%$ of school-aged children and was associated with an increased risk of experiencing severe symptoms consistent with mental health problems. Although peer victimization starts to decrease by the end of childhood, individuals in the severe trajectory group were still being exposed to the highest level of victimization in early adolescence. Therefore, antibullying interventions should begin before enrolment in the formal school system. Experi- mental studies aimed at preventing victimization would provide information about both the efficacy of preventive measures and the potentially causal role of victimization.

\section{References}

1. Finkelhor D, Turner HA, Hamby S. Let's prevent peer victimization, not just bullying. Child Abuse Negl 2012;36:271-4

2. Reijntjes A, Kamphuis JH, Prinzie P, et al. Prospective linkages between peer victimization and externalizing problems in children: a meta-analysis. Aggress Behav 2011;37:215-22

3. Reijntjes A, Kamphuis $\mathrm{JH}$, Prinzie $\mathrm{P}$, et al. Peer victimization and internalizing problems in children: a meta-analysis of longitudinal studies. Child Abuse Negl 2010;34:244-52.

4. Arseneault L, Bowes $L$, Shakoor S. Bullying victimization in youths and mental health problems: 'Much ado about nothing'? Psychol Med 2010;40:717-29.

5. Bowes L, Joinson C, Wolke $D$, et al. Peer victimisation during adolescence and its impact on depression in early adulthood: prospective cohort study in the United Kingdom. BMJ 2015;350:h2469.

6. Fisher HL, Moffitt TE, Houts RM, et al. Bullying victimisation and risk of self harm in early adolescence: longitudinal cohort study. BMJ 2012;344:e2683.

7. Kim YS, Leventhal BL, Koh YJ, et al. School bullying and youth violence: Causes or consequences of psychopathologic behavior? Arch Gen Psychiatry 2006;63:1035-41.

8. Moore SE, Norman RE, Sly PD, et al. Adolescent peer aggression and its association with mental health and substance use in an Australian cohort. J Adolesc 2014;37:11-21.

9. Zwierzynska K, Wolke D, Lereya TS. Peer victimization in childhood and internalizing problems in adolescence: a prospective longitudinal study. $J$ Abnorm Child Psychol 2013;41:309-23.

10. Arseneault L, Cannon M, Fisher HL, et al. Childhood trauma and children's emerging psychotic symptoms: a genetically sensitive longitudinal cohort study. Am J Psychiatry 2011;168:65-72.

11. Geoffroy MC, Boivin M, Arseneault L, et al. Associations between peer victimization and suicidal ideation and suicide attempt during adolescence: results from a prospective population-based birth cohort. J Am Acad Child Adolesc Psychiatry 2016;55:99-105.

12. Schreier A, Wolke D, Thomas K, et al. Prospective study of peer victimization in childhood and psychotic symptoms in a nonclinical population at age 12 years. Arch Gen Psychiatry 2009;66:527-36.

13. Ttofi MM, Farrington DP. Effectiveness of school-based programs to reduce bullying: a systematic and meta-analytic review. J Exp Criminol 2011;7:27-56.

14. Vreeman RC, Carroll AE. A systematic review of school-based interventions to prevent bullying. Arch Pediatr Adolesc Med 2007;161:78-88.

15. Merikangas KR, He JP, Burstein M, et al. Lifetime prevalence of mental disorders in US adolescents: results from the National Comorbidity Survey ReplicationAdolescent Supplement (NCS-A). J Am Acad Child Adolesc Psychiatry 2010;49:980-9.

16. Lereya ST, Copeland WE, Zammit S, et al. Bully/victims: a longitudinal, populationbased cohort study of their mental health. Eur Child Adolesc Psychiatry 2015; 24:1461-71.

17. Arseneault L, Walsh E, Trzesniewski K, et al. Bullying victimization uniquely contributes to adjustment problems in young children: a nationally representative cohort study. Pediatrics 2006;118:130-8.

18. Côté SM, Orri M, Brendgen M, et al. Psychometric properties of the Mental Health and Social Inadaptation Assessment for Adolescents (MIA) in a population-based sample. Int J Methods Psychiatr Res 2017. doi:10.1002/mpr.1566 [Epub ahead of print].

19. Ladd GW, Kochenderfer-Ladd B. Identifying victims of peer aggression from early to middle childhood: analysis of cross-informant data for concordance, estimation of relational adjustment, prevalence of victimization, and characteristics of identified victims. Psychol Assess 2002;14:74-96.

20. Willms DJ, Shields M. A measure of socioeconomic status for the National Longitudinal Study of Children: Fredericton (NB): Atlantic Center for Policy Research in Education (University of New Brunswick and Statistics Canada); 1996.

21. National longitudinal survey of children and youth: overview of survey instruments for 1994-1995. Data collection cycle 1. Ottawa: Statistics Canada; [modified 2007].

22. Boivin M, Perusse D, Dionne G, et al. The genetic-environmental etiology of parents' perceptions and self-assessed behaviours toward their 5-month-old infants in a large twin and singleton sample. J Child Psychol Psychiatry 2005;46:612-30.

23. Radloff LS. The CES-D Scale: a self-report depression scale for research in the general population. Appl Psychol Meas 1977;1:385-401.

24. Achenbach TM, Edelbrock C, Howell CT. Empirically based assessment of the behavioral/emotional problems of 2- and 3-year-old children. J Abnorm Child Psychol 1987;15:629-50. 
25. Offord DR, Boyle MH, Racine Y. Ontario Child Health Study: correlates of disorder. J Am Acad Child Adolesc Psychiatry 1989;28:856-60.

26. Tremblay RE, Desmarais-Gervais L, Gagnon C, et al. The Preschool Behaviour Questionnaire: stability of its factor structure between cultures, sexes, ages and socioeconomic classes. Int J Behav Dev 1987;10:467-84.

27. Allgaier AK, Frühe B, Pietsch K, et al. Is the Children's Depression Inventory short version a valid screening tool in pediatric care? A comparison to its fulllength version. J Psychosom Res 2012;73:369-74.

28. Kovacs M. The Children's Depression Inventory (CDI). Psychopharmacol Bull 1985; 21:995-8.

29. Nagin DS, Odgers CL. Group-based trajectory modeling in clinical research. Annu Rev Clin Psychol 2010;6:109-38.

30. Azur MJ, Stuart EA, Frangakis C, et al. Multiple imputation by chained equations: What is it and how does it work? Int J Methods Psychiatr Res 2011;20:40-9.

31. Sourander A, Gyllenberg D, Klomek AB, et al. Association of bullying behavior at 8 years of age and use of specialized services for psychiatric disorders by 29 years of age. JAMA Psychiatry 2016;73:159-65.

32. Kaltiala-Heino R, Fröjd S, Marttunen M. Involvement in bullying and depression in a 2-year follow-up in middle adolescence. Eur Child Adolesc Psychiatry 2010;19:45-55.

33. Stapinski LA, Bowes $L$, Wolke $D$, et al. Peer victimization during adolescence and risk for anxiety disorders in adulthood: a prospective cohort study. Depress Anxiety 2014;31:574-82.

34. Bond L, Carlin JB, Thomas L, et al. Does bullying cause emotional problems? A prospective study of young teenagers. BMJ 2001;323:480-4.

35. Turecki G, Brent DA. Suicide and suicidal behaviour. Lancet 2016;387:1227-39

36. Renaud J, Berlim MT, McGirr A, et al. Current psychiatric morbidity, aggression/impulsivity, and personality dimensions in child and adolescent suicide: a case-control study. J Affect Disord 2008;105:221-8.

37. Dumais A, Lesage A, Alda M, et al. Risk factors for suicide completion in major depression: a case-control study of impulsive and aggressive behaviors in men. Am J Psychiatry 2005;162:2116-24.

38. Turecki G. Dissecting the suicide phenotype: the role of impulsive-aggressive behaviours. J Psychiatry Neurosci 2005;30:398-408.

39. Pinto Pereira SM, Geoffroy MC, Power C. Depressive symptoms and physical activity during 3 decades in adult life: bidirectional associations in a prospective cohort study. JAMA Psychiatry 2014;71:1373-80.

\section{Competing interests: None declared.}

This article has been peer reviewed.

Affiliations: McGill Group for Suicide Studies (Geoffroy, Renaud, Perret, Turecki) and Manulife Centre for Breakthroughs in Teen Depression and Suicide Prevention (Renaud), Douglas Mental Health University Institute; McGill University (Geoffroy, Renaud, Perret, Turecki), Montréal, Que.; Research Unit on Children's Psychosocial Maladjustment (Geoffroy, Boivin, Turecki, Vitaro, Brendgen, Tremblay, Côté), Montréal and Québec, Que.; Université Laval (Boivin), Québec, Que.; Institute of Genetic, Neurobiological, and Social Foundations of Child Development at Tomsk State University (Boivin), Tomsk, Russian Federation; Institute of Psychiatry, Psychology and Neuroscience (Arseneault), King's College London, London, UK; Centre de recherche INSERM U1219 (Michel, Salla, Côté), Université de Bordeaux, Bordeaux, France; Université de Montréal (Vitaro, Tremblay, Côté); CHU Sainte-Justine Research Center (Vitaro, Brendgen); Université du Québec à Montréal (Brendgen), Montréal, Que.; University College Dublin (Tremblay), Dublin, Ireland
Contributors: Marie-Claude Geoffroy, Michel Boivin, Louise Arseneault and Sylvana Côté conceived and designed the study. Miche Boivin, Gustavo Turecki, Frank Vitaro, Richard Tremblay and Sylvana Côté acquired the data. Marie-Claude Geoffroy analyzed the data, and all of the authors interpreted the data. MarieClaude Geoffroy, Michel Boivin, Louise Arseneault and Sylvana Côté wrote the initial drafts, and Johanne Renaud, Léa Perret, Gustavo Turecki, Gregory Michel, Julie Salla, Frank Vitaro, Mara Brendgen and Richard Tremblay revised the paper for important intellectual content. All of the authors gave final approval of the version to be published and agreed to be accountable for all aspects of the work.

Funding: Marie-Claude Geoffroy holds a Junior 1 salary award from the Fonds de recherche du Québec en santé (FRQS). Louise Arseneault is the Mental Health Leadership Fellow for the UK Economic and Social Research Council. Gustavo Turecki holds a Canada Research Chair (Tier 1) and a National Alliance for Research on Schizophrenia and Depression Distinguished Investigator Award. This study was conducted with funding from the FRQS through the Quebec Network on Suicide, Mood Disorders and Related
Disorders (Johanne Renaud and Gustavo Turecki) and the Canadian Institutes of Health Research (CIHR; OGE 111395 and MOP 114984 awarded to Michel Boivin and Sylvana Côté). The larger Quebec Longitudinal Study of Child Development was also supported by funding from the Quebec provincial government's Ministry of Health and Ministry of Family Affairs, the Lucie and André Chagnon Foundation, the FRQS, the Fonds de recherche du Québec Société et culture, Canada's Social Sciences and Humanities Research Council, the CIHR, the CHU Sainte-Justine Research Center and the Institut de la statistique du Québec. The funders had no role in study design, data analysis, the decision to publish or preparation of the manuscript.

Acknowledgements: The authors thank Alain Girard, Xuecheng Liu and Qian Xu of the Research Unit on Children's Psychosocial Maladjustment for their contributions to the statistical analysis and all participants of the Quebec Longitudinal Study of Child Development.

Accepted: Aug. 8, 2017

Correspondence to: Marie-Claude Geoffroy, marie-claude.geoffroy@mcgill.ca 